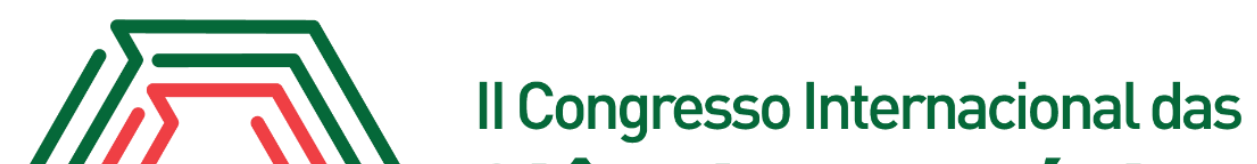 Ciências Agrárias COINTER - PDVAgro 2017
}

\section{PRODUÇÃO E QUALIDADE FISIOLÓGICA DE SEMENTES DE GERGELIM EM FUNÇÃO DA ADUBAÇÃO}

\author{
Apresentação: Pôster
}

Thiago Pereira de Paiva Silva ${ }^{1}$; Aldifran Rafael de Macedo $^{2}$; Erivan Isídio Ferreira ${ }^{3}$; Márcio Dias Pereira ${ }^{4}$

\section{Introdução}

O gergelim (Sesamum indicum L.) é uma das oleaginosas mais cultivadas no mundo e possui ótima adaptabilidade à regiões semiáridas e áridas. Sua produção é de grande importância econômica e social para as populações rurais do nordeste brasileiro, por ser de fácil cultivo, apresentar tolerância à estiagem, gerar renda e trabalho e por ser fonte de alimento para pequenos e médios produtores. No entanto, a qualidade das sementes ofertadas é baixa, o que ocasiona queda considerável na produção por área cultivada.

De acordo com Ferreira et. al. (2012), a cultura do gergelim possui bom desenvolvimento em solos moderadamente férteis, com boa drenagem e textura leve. Trata-se de uma cultura bastante exigente em macro e micronutrientes, sendo o nitrogênio e o fósforo nutrientes limitantes. Embora as necessidades nutricionais dos diferentes materiais genéticos de gergelim disponíveis ainda não estejam completamente estabelecidas, a adubação orgânica tem sido uma alternativa ao seu cultivo.

Desse modo, o uso de fontes orgânicas de nutrientes deve suprir as demandas da planta para cada nutriente. Entretanto, existe carência de informações quanto a adubação orgânica ou combinada com a química na cultura do gergelim, no que se refere aos componentes de desenvolvimento, produção e qualidade de sementes.

Portanto, o objetivo deste trabalho foi avaliar o efeito de diferentes tipos de adubação na

\footnotetext{
${ }^{1}$ Agronomia, Universidade Federal do Rio Grande do Norte, thiago.pereira_14@hotmail.com

2 Agronomia, Universidade Federal do Rio Grande do Norte, aldifranprojetos@ gmail.com

3 Agronomia, Universidade Federal do Rio Grande do Norte, erivanisidio@ gmail.com

${ }^{4}$ Doutor, Universidade Federal do Rio Grande do Norte, marcioagron@ yahoo.com.br
} 
produção do gergelim e na qualidade das sementes produzidas.

\section{Fundamentação Teórica}

O óleo extraído das sementes de gergelim tem possibilidade de uso na indústrias alimentar, química e farmacêutica. Do ponto de vista econômico, o gergelim tem se destacado no cenário nacional e internacional, apresentando tendência de crescimento (CRUZ et al., 2010). A qualidade do seu óleo, bem como a produção e a qualidade de suas sementes, podem ser influenciadas pelo tipo de adubo utilizado.

Segundo Perin et al. (2010) a fertilidade do solo ocasiona incremento nas características vegetativas e produtivas das plantas, no entanto o parâmetro adubação é um dos assuntos mais pesquisados e controversos, apresentando respostas diferentes quando se avaliam locais e épocas de cultivo, ou mesmo cultivares. Em razão disso, é necessário definir o efeito dos diferentes tipos de adubos orgânicos na produção de sementes de alta qualidade fisiológica.

As pesquisas que tratam sobre o controle de qualidade de sementes de gergelim se justificam pela potencialidade da espécie e pela escassez de informações relacionadas a diferentes fatores, como a nutrição e a disponibilidade hídrica na qualidade fisiológica de suas sementes (QUEIROGA et al., 2010). Contudo, de acordo com Favarato et al. (2012) trabalhos que objetivam relacionar a adubação e nutrição das plantas com a qualidade fisiológica das sementes são em número reduzido e os resultados nem sempre são concordantes.

\section{Metodologia}

O experimento foi conduzido em casa de vegetação, localizada no município de Caiçara do Rio do Vento/RN - Brasil (latitude $05^{\circ} 48^{\prime} 04,73$ ” S, longitude $35^{\circ} 55^{\prime} 49,00$ ” W), cuja altitude média é de 317 m. O clima é do tipo BSh, segundo a classificação de Köppen et al. (1928) com registro de temperatura média de $25,1^{\circ} \mathrm{C}$.

As parcelas foram constituídas de vasos com capacidade para 18 litros, preenchidos com 2 litros de brita ( $\mathrm{n}^{\mathrm{o}}$ zero), 10 litros (nos 2/3 inferiores do volume do vaso) de solo tipo neossolo regolítico e textura areia franca e 6 litros da mistura de solo com a fonte de adubo na quantidade indicada por balde.

O delineamento experimental utilizado foi o inteiramente casualizado, com quatro repetições de seis plantas, sendo quatro tipos de adubo diferentes. As condições de adubação por balde foram: a) testemunha - sem adubação; b) composto orgânico - 123,3 g de composto; c) composto orgânico 
em conjunto com a aplicação de NP - 123,3 g de composto; 5,4 g de sulfato de amônia (21\% de N); 18,2 g de superfosfato triplo (41\% de P2O5) e d) resíduo sólido de biodigestor - 153,0 g de resíduo sólido de biodigestor).

A semeadura foi realizada utilizando-se 20 sementes de gergelim da variedade CNPA G4 a uma profundidade média de $1 \mathrm{~cm}$ em cada balde. Dado o estabelecimento da cultura, aproximadamente 20 dias após a semeadura (DAS), foi realizado o desbaste mantendo-se seis plantas por vaso.

O número total de cápsulas emitidas por planta foi computado a partir do lançamento das primeiras cápsulas, a cada sete dias até o fim da emissão de flores e formação de novas cápsulas. A produção total de grãos foi determinada a partir da coleta de todas as cápsulas maduras de cada planta, das quais as sementes foram retiradas e pesadas.

As sementes obtidas no cultivo foram acondicionadas em sacos de papel do tipo krafit e encaminhadas ao laboratório para a realização das análises. O teste de germinação foi realizado conforme as Regras para Análise de Sementes (RAS, 2009). As avaliações foram realizadas diariamente, até o $7^{\circ}$ dia após a semeadura, para se obter o índice de velocidade de germinação (IVG), conforme Maguire (1962), computando-se o número de sementes germinadas por dia.

As médias dos tratamentos foram submetidas a análise de variância e, quando significativas, comparadas pelo teste de Tukey (1 e 5\%) utilizando-se o software AgroEstat (BARBOSA, J. C.; MALDONADO JÚNIOR, W, 2015).

\section{Resultados e Discussões}

Para o número total de cápsulas (Tabela 1), observou-se que o melhor potencial produtivo foi obtido com a utilização da mistura do composto orgânico com o NP (média de 33,25 cápsulas por planta). Com esse resultado corrobora o exposto por Ferreira (2012), que observou que o aumento do número de cápsulas para plantas com adubação orgânica pode estar associada às características do adubo, que além de servir como fonte nutricional para as plantas, também pode funcionar como um regulador de absorção de nutrientes.

Com relação a produção de grãos (Tabela 1), o tratamento em que foi utilizado o composto + NP também apresentou-se como o mais promissor (média de 15,5 grãos), seguido pelo tratamento que utilizou o resíduo biodigestor (média de 11 grãos). Os demais tratamentos não diferiram entre si e apresentaram os mais baixos valores de produção. $O$ efeito positivo da adubação comercial 
combinada com a orgânica já foi comprovada para outras culturas oleaginosas. O uso da adubação organomineral na cultura da mamoneira resultou em produtividade quase duas vezes superior ao obtido para plantas cultivadas apenas com adubos químicos (SEVERINO et al. 2006). Além disso, Silva et al. (2016) concluíram que o aumento da dose de resíduo de biodigestor, na presença de irrigação, promove aumento direto do número de frutos/planta de gergelim.

Quanto à germinação das sementes produzidas durante o cultivo submetido aos diferentes tipos de adubo (Tabela 1), àquelas relacionadas ao tratamento composto + NP tiveram germinação inferior àquelas obtidas de plantas cultivadas com o adubo de resíduo de biodigestor, no entanto, acima do percentual mínimo desejável para germinação $(89,5 \%)$ e não diferiu das sementes obtidas do cultivo sem adubação e com adubo orgânico. Este comportamento pode ter se dado em virtude da rápida liberação do nitrogênio, que foi potencializado pela aplicação apenas em fundação. $\mathrm{O}$ nitrogênio pode influenciar na qualidade fisiológica das sementes, mas este efeito depende das condições ambientais e do estágio de desenvolvimento em que este nutriente é fornecido para as plantas (COSTA et al., 2008).

Com relação ao Índice de Velocidade de Germinação - IVG, observou-se que o tipo de adubo utilizado afetou a velocidade de germinação, de modo que a utilização do composto ou sua associação com o NP resultaram em menor IVG. As plantas cultivadas com o resíduo do biodigestor produziram sementes cujo IVG não apresentaram diferença significativa da testemunha. Já as sementes obtidas do cultivo no qual se utilizou composto orgânico ou composto orgânico associado a adubação mineral, também não diferem entre si.

Tabela 1.Efeito da adubação na produção de gergelim e avaliação do potencial germinativo e Índice de Velocidade de Germinação de sementes. Fonte: Própria

\begin{tabular}{ccccc}
\hline Adubos & $\begin{array}{c}\mathrm{N}^{\circ} \text { médio de } \\
\text { cápsulas/planta }\end{array}$ & $\begin{array}{c}\text { Peso médio de grãos } \\
(\mathrm{g})\end{array}$ & $\begin{array}{c}\text { Germinação } \\
(\%)\end{array}$ & $\begin{array}{c}\text { Índice de } \\
\text { Velocidade de } \\
\text { Germinação (IVG) }\end{array}$ \\
\hline Testemunha & $10,50 \mathrm{c}$ & $5,75 \mathrm{c}$ & $97,5 \mathrm{ab}$ & $16,08 \mathrm{ab}$ \\
Composto & $15,25 \mathrm{bc}$ & $7,50 \mathrm{c}$ & $92,5 \mathrm{ab}$ & $13,89 \mathrm{c}$ \\
Composto + NP & $33,25 \mathrm{a}$ & $15,50 \mathrm{a}$ & $89,5 \mathrm{~b}$ & $14,81 \mathrm{bc}$ \\
Resíduo biodigestor & $20,50 \mathrm{~b}$ & $11,00 \mathrm{~b}$ & $100,0 \mathrm{a}$ & $16,51 \mathrm{a}$ \\
\hline
\end{tabular}

Médias seguidas pela mesma letra na coluna, não diferem entre si pelo Teste de Tukey $(\mathrm{P}<0,01$ e 0,05$)$.

\section{Conclusões}


O uso do composto orgânico associado a adubação mineral permitiu a produção de maior número de cápsulas e peso médio de grãos. No entanto, os resultados obtidos neste trabalho não são conclusivos em relação ao efeito da adubação na qualidade fisiológica de sementes de gergelim.

\section{Referências}

BARBOSA, J. C.; MALDONADO JÚNIOR, W. Experimentação agronômica \& AgroEstat: sistema para análises estatísticas de ensaios agronômicos. Jaboticabal, 2015.

BRASIL; Regras para analise de sementes. Ministério da Agricultura, Pecuária e Abastecimento. Secretaria de Defesa Agropecuária, Brasília/DF: MAPA/ACS, 2009.

COSTA, R.C.L., Lobato, A.K.S., Oliveira Neto, A.F., Maia, P.S.P., Alves, G.A.R. 2008. Biochemical and physiological responses in two Vigna unguiculata (L.) Walp. cultivars under water stress. Journal of Agronomy, 7 (1): 98-101.

CRUZ, Robenia Nunes et al; Diagnóstico econômico do cultivo de gergelim no assentamento Nova Vida, PB. Anais do IV Congresso Brasileiro de Mamona e I Simpósio Internacional de Oleaginosas Energéticas. P. 363-368, Campina Grande, PB: Embrapa Algodão, 2010.

FAVARATO, Luiz Fernando et al. Adubação nitrogenada e qualidade fisiológica de sementes de trigo. Bragantia, v. 71, 2012.

FERREIRA, M. M.M., Eficiência comparativa da adubação orgânica no crescimento da mamoneira no semiárido paraibano Revista Verde de Agroecologia e Desenvolvimento Sustentável, v. 7, n.1, p.72-79, 2012.

FERREIRA, T. C. et al., Produção de Sesamum indicum L. Organico no Agreste Paraibano. Revista de Biologia e Farmácia, v.7, n. 2, p.112-11 FERREIRA, T. C. et al., Produção de Sesamum indicum L. Organico no Agreste Paraibano. Revista de Biologia e Farmácia, v.7, n. 2, p.112-118, 2012.8, 2012.

MAGUIRE, J.D. 1962 Speed of germination-aid in selection and evaluation for seedling emergence and vigor. Crop science, 2 (2): 176-177.

PERIN et al. Adriano; Desempenho do gergelim em função da adubação NPK e do nível de fertilidade do solo. Revista Acta Scientiarum. Agronomy Maringá, v. 32, n. 1, p. 93-98, 2010.

QUEIROGA, V.P., Borba, F.G., Almeida, K.V., Sousa, W.J.B., Jerônimo. J.F. Queiroga, D.A.N. 2010. Qualidade fisiológica e composição química das sementes de gergelim com distintas cores. RevistaAgro@mbiental On-line. 4(1):27-33

SEVERINO, L. S. et al. Produtividade e crescimento da mamoneira em resposta à adubação organica e mineral. Pesquisa Agropecuária Brasileira,v. 41, n. 5, p. 879-882, 2006.

SILVA, E. L. G., Crescimento e produção do gergelim em diferentes níveis de solução organomineral. Revista Verde de Agroecologia e Desenvolvimento Sustentável, v.11, n.3, p. 3338, 2016. 